OPEN ACCESS

Edited by:

J. B. Ruhl,

Vanderbilt University, United States

Reviewed by:

Nicola Wheen,

University of Otago, New Zealand

Robin Kundis Craig,

University of Southern California,

United States

*Correspondence:

Judy Lawrence

judy.lawrence@vuw.ac.nz

Specialty section: This article was submitted to

Climate Risk Management,

a section of the journal

Frontiers in Climate

Received: 02 July 2021 Accepted: 28 October 2021 Published: 19 November 2021

Citation:

Lawrence J, Allan S and Clarke L (2021) Inadequacy Revealed and the

Transition to Adaptation as Risk Management in New Zealand.

Front. Clim. 3:734726.

doi: 10.3389/fclim.2021.734726

\section{Inadequacy Revealed and the Transition to Adaptation as Risk Management in New Zealand}

\author{
Judy Lawrence ${ }^{1 *}$, Sylvia Allan ${ }^{2}$ and Larissa Clarke ${ }^{3}$ \\ ${ }^{1}$ Climate Change Research Institute, Te Herenga Waka Victoria University of Wellington, Wellington, New Zealand, ${ }^{2}$ Allan \\ Planning and Research Ltd., Lower Hutt, New Zealand, ${ }^{3}$ GNS Science, Lower Hutt, New Zealand
}

Climate change risk is rife with uncertainty. Increased frequency and intensity of flooding and drought and progressive sea-level rise, that compound and cascade and increase risk over time, pose particular difficulties for planning. The risks require institutional and governance frameworks that are tailored to such a dynamic environment. However, most planning frameworks and their practice focus on the societal need for certainty in space and time, to enable investment decisions to be made and activities to be undertaken with some stability. This means risk is framed in a static manner using time-bound planning methods, such as lines on maps and zoning, that lock in people and assets to areas of risk that are exposed to changing risk in time and space. The consequences are being increasingly revealed globally in deltas, inland low-lying areas and at the coast, and will increase unless planning practice becomes more adaptive and anticipates the risks early enough for adjustments to be made. Current decision-making frameworks in New Zealand have been revealed as inadequate for enabling changing and uncertain risks from climate change to be addressed. We discuss how practice under the existing planning framework has exposed people and assets to greater risk, and the challenges in the transition taking place in New Zealand toward an anticipatory adaptive approach. We chart the course of this transition and suggest how current law and practice can support and embed an adaptive direction within the institutional reforms underway for more effective climate risk management.

Keywords: climate change adaptation, risk management, institutional frameworks, sea-level rise, deep uncertainty, dynamic adaptive policy pathways

\section{INTRODUCTION}

Climate change brings with it some very different characteristics to many other hazards that risk management must address. While we are familiar with hazards such as extreme events that occur periodically, under changing climate many of the impacts are ongoing and getting worse, either by becoming more intense, more frequent, or slowly affecting people and places (IPCC, 2014). For example, temperature increases already challenge natural ecosystems, and human health and well-being tolerance levels, beyond change experienced in the past; prolonged periods without rainfall are generating decadal droughts and affecting livelihoods and contributing to migration; and rising sea levels will be ongoing for centuries. This is even if we meet the Paris target of holding the increase in the global average temperature 
to well below $2^{\circ} \mathrm{C}$ above pre-industrial levels and pursue efforts to limit the temperature increase to $1.5^{\circ} \mathrm{C}$ above pre-industrial levels, and after reaching net zero emissions domestically. We also face the prospect of concurrent risks that cascade and compound within and outside national jurisdictions, and which exhibit ongoing change and uncertainties (Challinor et al., 2018; Lawrence et al., 2020a). The adaptive capacity of people is built from lived and learned experience and through customs, norms, and laws (Adger et al., 2007). However, climate change creates the specter of the risk exceeding the adaptive capacity of people and natural systems (IPCC, 2018).

Interventions to ameliorate the damage from climate change impacts are required long before damages are experienced, due to the timeframes of the decisions taken today and the lifetimes of the activities being decided (Stafford Smith et al., 2011). Such interventions, however, are perceived as costly in the short term for uncertain future benefits (Hallegatte et al., 2012). Managing changing hazards through strong risk-avoidance approaches often implies greater initial costs, through preemptive adaptations or opportunities foregone. Since different sections in the community differ in the values they give to nearterm vs. long-term risks, such decisions are inevitably difficult and require the reconciling of conflicting views. Furthermore, socio-economic, and cultural development is likely to change those values over time. Changes in people's values and in their ability to respond to change in their economic and physical environment will affect their adaptive capacity (Smit and Wandel, 2006; Adger et al., 2007) and will also change community preferences. The value of assets at risk change over time, as will the technological and financial ability to undertake riskmanagement strategies. These factors compound in significance for decisions about enduring activities, for example, housing and infrastructure which remain for many decades in fixed locations. Consideration of the time horizons of decisions is critical for decision makers under changing climate conditions. However, the timeframe of current planning and political cycles often run counter to the long-term focus required for considering climate change risks.

Governments create institutions through laws and policies to limit risk of harm to society from human activities and to maintain stability for the functioning of social systems (Ruhl, 2012). However, in so doing institutional design and practice often fails to address changing risks and their inherent uncertainty. Ruhl (2010) suggested that adaptation that avoids hazards-supported by cross-policy linkages at all scales of governance-is necessary, alongside flexible regulatory instruments and conciliation processes embedded in a legal system that can respond to a dynamic world. In addition, provisions must be able to address risks that cannot be wellestimated today and must do so before evidence of significant damage is obvious.

Climate change risk is worsening, but uncertainties and ongoing change means that future states cannot be assigned probabilities. The 2019 International Standard ISO 14090 on adaptation to climate change embodies the notion of interdependent risks that have uncertainties and highlights the contribution that consideration of uncertainties has on the results of risk assessments. This means, that adaptation under changing and uncertain conditions must be robust (can operate under a range of futures) and flexible (changes can be made to decisions) (Lempert, 2019). This requires the relevant decisionmaking agencies to use proactive and anticipatory strategies that are underpinned by laws and policies to shift away from the reactive and protective post hoc behaviors of humans (Boston and Lawrence, 2018).

This paper presents a historical and forward-looking analysis of a process that has been underway in New Zealand for some decades and that reveals the inadequacies in the planning systems and risk management practices. These are now culminating in a major reform of the regulatory environment that can enable a transformation toward pre-emptive anticipatory decision making to address changing risks and build adaptive capacity. First, we take one example, sea-level rise, and show that planning frameworks and instruments have enabled static outcomes and are inadequate to address the problem of sea-level rise. The inadequacies have resulted in increased exposure of people and assets at risk, by locking in developments at the coast, making adaptation in the future extremely challenging. Second, we outline an agenda for institutional change currently being developed in New Zealand that explicitly seeks to address the dynamic and uncertain characteristics of changing climate through an anticipatory model of decision making.

Third, we provide some principles that can drive a transition to adaptation as risk management.

The analysis was undertaken by the authors (hazard, climate change experts and planners) as part of the Resilience to Nature's Challenges-Enabling Coastal Adaptation governmentfunded research program, and which is informing the legislative reform process. A mix of qualitative methods was used for the analysis including information from a number of sources (planning documents, published papers, direct contact with local government informants, case law under past and existing plans, and websites). Examples are presented of the most typical situations in which hazard exposure has occurred in New Zealand (Table 1). We have then provided examples of how some plans are trying to ensure better outcomes in the future (Table 2).

\section{THE SEA-LEVEL RISE CONUNDRUM-HISTORICAL LEGACY OF TRADITIONAL PRACTICE}

Sea-level rise is being observed now especially when there are perigean tides (king tides) around our estuaries and coastal locations (Stephens et al., 2018) with impacts on the function of roads, stormwater, and wastewater systems, cultural sites, human settlements, and coastal ecosystems. These impacts are also being exacerbated by more frequent intense storms when more permanent damage is sustained.

However, our institutional arrangements in law and our responses to the consequences of climate changes are based on the societal need for certainty in space and time to enable governments, businesses, and people to make investment decisions and undertake their daily lives with some stability. The 
TABLE 1 | Examples of planning practice that increase vulnerability to sea-level rise.

\begin{tabular}{ll}
\hline Example Characteristic Occurrence and policy context
\end{tabular}

Intensification of existing urban areas close to the coast and current sea level

Intensification or growth of small beach-side settlements

New areas of coastal development

Intensified development behind new coastal protection
Zoned and serviced for conventional urban development. Where infrastructure (e.g., road, railway, or port) has underground urban services which double as/are maintained as a form of coastal protection. Pressure for densification has led to ongoing increases of unabated development

Many traditional "bach" or "crib" settlements for temporary (holiday) occupation adjacent to a beach which pre-date any planning controls. Many have been subsequently zoned for residential use to meet the growing demand for permanent and holiday homes. Many small dwellings have become large or multi-units, the land has been infilled or settlements have grown spatially, leading to a doubling or more of the number of dwellings exposed to coastal processes

In rural localities where new low-density rural-residential subdivision has been permitted. The original subdivision may have included conditions on development to ensure that risks would be minimized and managed through (low) density control, coastal setbacks, and self-contained services. However, demand has resulted in further development via subdivision into small blocks and/or multi-unit development

Where communities exert pressure on local authorities to allow new or refurbished hard protection structures funded by that community
Very widespread in New Zealand, due to historic location of settlements in vulnerable areas with increasing intensification (e.g., residential, and commercial areas in Auckland, Dunedin, Tauranga, Napier, Petone and the Kapiti Coast north of Wellington and many mid-range coastal settlements) and current pressures to increase opportunities and supply of housing

The NZCPS recognizes that such existing areas may require ongoing hard protection but requires local authorities to consider options to reduce risks and avoid long-term social, environmental, and economic harm from coastal hazards. There is little evidence of consideration of long-term options

Found in many parts of New Zealand. Pressures are greatest in proximity to a major urban area (e.g., Omaha Beach, north of Auckland, a recent study on tsunami risk (Paulik et al., 2019) showed 448 dwellings in 1992 had increased to 1,147 by 2012, and 15 3-storeyed buildings in 1992 had become 39 by 2012) Such intensification and expansion of urban development should have only occurred following a risk assessment. More permanent residents result in changes in community perceptions and values often resulting in greater pressure on local authorities to provide hard protection, or to enable residents undertaking their own protection resulting in problems such as "end" effects on other properties

In many parts of New Zealand often from the "life-style" boom of the past 30 years. Expansion of planned subdivisions during the development stages occurs (e.g., Boatshed Bay, Snells Beach, where an original 25 -lot subdivision intensified to 71 lots, some containing multiple dwellings)

Such "planning creep," is considered in successive applications, each of which is seen to add little additional risk. This approach is contrary to policies in the NZCPS which requires that land use change which increases the risk of harm from coastal hazards, is avoided. Councils also find it difficult to avoid developments in coastal risk areas where empty, previously consented subdivisions, exist

Some such proposals have been rejected (e.g., Pakawau in Tasman District). However, there are many examples of councils funding protection proposals e.g., Haumoana in Hawkes Bay with a population of 1,150 where the council funded $\$ 600,000$ for rock revetment protection. At nearby Clifton, population 770 , the same council, and two local landowners are investing $\$ 2.8 \mathrm{M}$ over 35 years to protect a road, a camping ground, and a small settlement. At Waihi Beach in the eastern Bay of Plenty, population 3000, the council evaluated options and obtained consent to build a replacement sea wall and undertake dune enhancement to protect existing properties. Funding is through a targeted rating area, where capital and maintenance is largely covered by those who benefit and $25 \%$ of the costs are funded via related council program (the wall has been extended, recently on the same basis to address "end effects" of the structure)

The NZCPS requires that options to hard protection for existing settlements must be considered. Each of these examples has been considered through comprehensive consent processes, including an evaluation in terms of the NZCPSThe NZCPS requires that options to hard protection for existing settlements must be considered. Each of these examples has been considered through comprehensive consent processes, including an evaluation in terms of the NZCPS 
TABLE 1 | Continued

\begin{tabular}{|c|c|c|}
\hline Example & Characteristic & Occurrence and policy context \\
\hline Coastal river-mouth & $\begin{array}{l}\text { Development of settlements in dynamic coastal } \\
\text { river mouths are a legacy of early settlement } \\
\text { near navigable rivers and continued } \\
\text { development at that site based on existing } \\
\text { infrastructure. Significant alteration of natural } \\
\text { systems for protection has enabled } \\
\text { development and reinvestment behind them to } \\
\text { continue to occur }\end{array}$ & $\begin{array}{l}\text { Growth pressures have led to ongoing protection in such localities } \\
\text { (e.g., Hokitika on New Zealand's South Island west coast is protected } \\
\text { by seawalls and groins funded by a targeted rating area. }{ }^{\text {a,b }} \text { Regional } \\
\text { coastal and district planning processes currently under review create } \\
\text { opportunities for greater scrutiny of growth plans and modifications to } \\
\text { the sea wall, including considering the feasibility of remaining in the } \\
\text { dynamic environment affected by sea-level rise, river dynamics and the } \\
\text { risk of seismic hazards, or of retreating) }\end{array}$ \\
\hline
\end{tabular}

${ }^{a}$ https://www.wcrc.govt.nz/repository/libraries/id:2459ikxj617q9ser65rr/hierarchy/Documents/Services/Special\%20Rating\%20Districts/Hokitika\%20Seawall/Asset\%20Management \%20Plans/Hokitika\%20Seawall\%20Asset\%20Management\%20Plan\%202014\%20-\%202017.doc.

${ }^{b}$ https://www.stuff.co.nz/national/politics/local-democracy-reporting/121546660/plan-now-for-hokitika-retreat-from-the-sea--councillor-warns.

TABLE 2 | Examples of proactive planning that will reduce risk over time.

Example Description

Marlborough District

Council, Regional Planning

Approach

Mapua Township, Tasman District

Whakatane District

This local authority, which has a long and very complex land/sea interface, has recently comprehensively reviewed all its RMA planning documents. For the first time in New Zealand, policy has been included in the Regional Policy Statement (the highest-level policy document, which must be given effect to in all levels of RMA decision-making in the region) which has largely adopted the MfE guidance on sea-level rise allowances, undertaking to apply Dynamic Adaptive Pathways Planning (DAPP) by working with local communities to develop an action plan for sea-level rise responses. A separate Climate Change chapter identifies climate change effects as one of the major issues facing the region and identifies such future planning as the main method to address the issue

Parts of the small seaside township of Mapua in Tasman District (current population, 5000) were identified as particularly vulnerable to coastal erosion. The council undertook a comprehensive structure planning process with the local community to determine how future growth should be provided for. As part of this process, new areas on higher hillsides, able to be accessed and serviced, were rezoned for development, while the older more vulnerable areas became "closed zones" with any further development prohibited. Strong policy in the natural resources plan supported the transitional planning toward a less vulnerable future settlement

Whakatane District has $54 \mathrm{~km}$ of coastline, much of it vulnerable to sea-level rise and other coastal natural hazards. The district plan (operative since 2017) identifies existing erosion areas, and 2060 and 2100 hazard lines on the planning maps, along with strong policy and rules to manage development within hazard areas. Inland to the 2100 hazard line, existing buildings can be maintained, but new buildings and other structures face increasing consent difficulty, the closer to the coast that they are. Easier consenting paths are provided for new dwellings if an alternative building site for future relocation is provided. Such sites must be held available (within the same legal ownership title) for eventual building relocation. Relocation is triggered when the line of mean high-water springs is at $20 \mathrm{~m}$ from the closest point of the building. Draft conditions in the plan indicate what the council will require owners to do (including notations on the land title) if consent is granted. Otherwise, rules and policy make it very difficult to obtain consent for new buildings. Similarly, there are strong consenting barriers which mean that any form of coastal protection, other than methods such as dune planting, is unlikely to get consent. The processes which have led to these plan provisions are in line with DAPP, and the approach is consistent with the NZCPS

response has been to use static decision frameworks that bias responses toward retrospective, rather than anticipatory planning (Manning et al., 2015), using "protective" measures. These in turn have given people a false sense of security, leading to increased risk due to intensification of investment at the coast, driven by widespread preference to be near the coast for the apparent values it affords people (Haasnoot et al., 2021). This is a global trend. However, land use planning decisions to date have been made under a period of relatively quiescent climate, within a range of variability that humans have adjusted to-global warming is changing the range now being experienced (IPCC, 2018). Greater frequency of weather extremes across the world has led to much discussion in the literature about adaptation to changing risk and the relative effectiveness of "protect," "accommodate," "advance" or "retreat" strategies to manage the risks (Haasnoot et al., 2021). New Zealand is no exception.

The New Zealand institutional framework for addressing hazards and climate risks is based on a set of administrative traditions (Van Buuren et al., 2018) largely devolved to local government which comprises 11 regional councils, 61 territorial authorities ( 11 city councils and 50 district councils) and six unitary councils (territorial authorities with regional responsibilities). White and Lawrence (2020) charted the eras of institutional response to New Zealand riskscapes showing how legacies have arisen and evolved from past planning and development decisions. For example, the widespread natural forest clearance in catchments and lowland areas associated with settlement and taming a new land resulted in the loss of 
flood attenuation and storage capacity of the natural ecosystems, which increased flooding and soil erosion. What followed was the "protect" regime under the Soil Conservation and Rivers' Control Act 1941 which heralded the construction of some of the largest flood protection works and coastal protection structures in the country. Historically, human development took place near the means of transport-rivers and the coasts. Following a 1953 version, a Town and Country Planning Act emerged in the 1970s that had an objective that protected settlements by controlling land uses and was supported by hazards mapping. However, it was not until the 1990s that a more integrated statute emerged across land and water, which included a "reduction, avoidance, and mitigation of hazards" purpose, in the Resource Management Act 1991 (RMA). This statute, largely administered by local government, mandated national directions for coastal hazard management but did not initially include the growing recognition of the impacts of climate change. The first New Zealand Coastal Policy Statement (NZCPS) prepared under the RMA, in 1994, was underpinned by a "precautionary" approach. The NZCPS recognized the potential for climate change to affect coastal activities and required local authorities to plan for the inland migration of coastal features, and for new settlements and subdivisions to be located and designed to avoid the need for coastal protection. It was not until 2004 that "the effects of climate change" was added into the RMA as a matter which must be carefully considered in all planning decisions. The 2010 update of the NZCPS added a timeframe of "at least 100 years" when planning for climate change and directed specific planning responses for new and existing development in coastal areas subject to sea-level rise risks.

Meanwhile planning practice largely continued along a preferred "mitigation" of hazards route using "protection" and "accommodation" measures. When such mitigation measures were insufficient after weather-related disasters, limited insurance has been paid as a last resort to households from the Government's Disaster Fund. ${ }^{1}$ This has enabled building back in the same hazard-exposed locations, rather than enabling rebuilding in areas that reduce risk (Lawrence and Saunders, 2017). Development has increased in areas of hazard risk regardless of the provision of increasingly clear national-level climate change planning guidance for assessing and managing coastal hazards (MfE, 2017). This guidance has been informed by successive IPCC reports which indicate increasingly damaging and complex climate change impacts, and the availability of new decision-making tools for pre-emptive anticipatory risk management developed in the last 10 years (Lawrence and Haasnoot, 2017; Lawrence et al., 2019b) and the value of early engagement with affected interests in low-lying coastal areas (Schneider et al., 2020).

To better understand the long-term outcomes of current planning practice in a context of ongoing sea-level rise, the authors undertook analysis of typical situations where

\footnotetext{
${ }^{1}$ The Earthquake Commission Act 1993 provides insurance funding for residential property damage from natural disasters, administered by the Earthquake Commission, which is funded through a levy on private property insurance, for underwriting damages up to NZ\$150,000 per claim.
}

intensification of development, or new development, has occurred in relatively hazardous coastal locations across New Zealand. Examples (Table 1) show how practice based on the current regulatory environment is creating a legacy of exposed inhabitants and their services that increase vulnerability over time and if sea level rises faster than current projections. This is happening through intensification and growth of existing large and small urban areas and through intensified and new developments behind protection structures and at coastal and river mouth locations (localities shown in Figure 1).

There are only a few examples (Table 2) of local authorities taking pro-active steps to set in place planning regimes that will actively reduce risk over time and that are in line with the approaches recommended in the national coastal planning guidance (dynamic adaptive planning and community engagement at its core) (MfE, 2017). These remain exceptions in a wider and unintended regime of gradually increasing exposure to coastal hazards from sea-level rise.

In summary, legacy effects of plans which include land zoned for residential development in areas which would today be regarded as unsuitable for new development because of the coastal hazards, have since accommodated a lot of intensification (e.g., parts of Christchurch, Tauranga, Petone and Kapiti Coast in the Wellington region, Auckland, Napier). This has happened because of favorable zoning and a general inability to prevent intensification of earlier low-density development.

In terms of new development, in the past two decades there are only a few proposals in coastal hazard areas which have been successfully repelled, ${ }^{2}$ notably on the Kina Peninsula (13 lots) near Nelson and at Bay View near Napier (about 30 lots). The councils around Napier City have proactively undertaken a comprehensive coastal compartment assessment of coastal risk and have developed a Coastal Hazards Strategy using a hybrid DAPP process to assess options, develop pathways, and monitor signals of change which include triggers to identify when decisions should be made to change paths as sea level rises (Lawrence et al., 2019a).

\section{THE INSTITUTIONAL CHANGE AGENDA}

An independent review of New Zealand's RMA and its intersection with related legislation such as the Local Government Act 2002, the Land Transport Management Act 2003 and the Climate Change Response (Zero Carbon) Amendment Act $2019^{3}$ was completed in 2020. The review was motivated by a natural environment under significant pressure, urban areas struggling to keep pace with population growth, an urgent need to reduce carbon emissions and adapt to climate change, the need for a more effective role for iwi/Māori in the resource management system that is consistent with the

\footnotetext{
${ }^{2}$ These two examples were challenged at the Environment Court-Carter Holt Harvey Ltd HBU v Tasman District Council Decision No. (2013) NZEnvCt 25, and Fore World Developments Limited v Napier City Council W029/2006 (2006) NZEnvC 120.

${ }^{3}$ Amending the Climate Change Response Act 2002.
} 


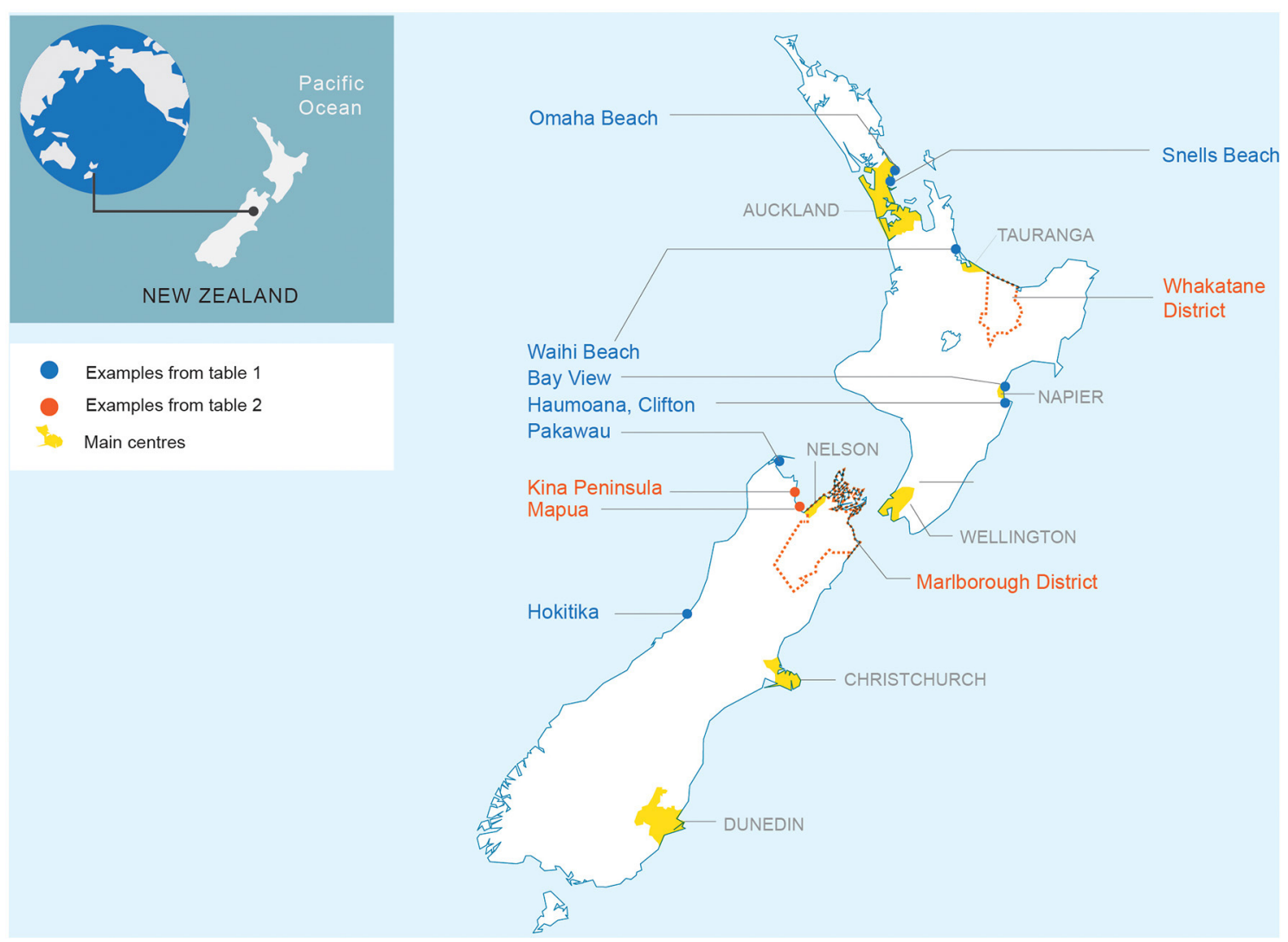

FIGURE 1 | Location of New Zealand and examples cited in Tables 1, 2.

Treaty of Waitangi, and a need for greater system efficiency and effectiveness (Randerson, 2020).

The review recognized the value of a more strategic and anticipatory planning system and recommended three new statutes. First, a Strategic Planning Act to provide a framework for mandatory regional spatial planning for the land and marine coastal areas, ${ }^{4}$ which emphasizes the importance of a long term view out at least 100 years, that enables areas to be excluded from development, that provides that policy and plans are subject to review every 10 years or earlier if significant issues arise, and which incorporates significant stakeholder and community involvement. Second, a Natural and Built Environment Act to set environmental baselines, while keeping the important synergies between the natural and human environment together, increasing national direction and instituting a national monitoring, audit, and reporting system. Third, a Managed Retreat and Climate Change Adaptation Act specifically to address the complexities of managing the effects of climate change, such as which level of governance manages and funds responses to climate change risks and how to address existing uses and managed retreat. Climate change mitigation and adaptation and natural hazards risk reduction would be integrated into all three statutes and would be informed by the

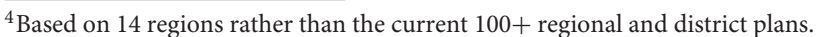

National Risk Assessment and the National Adaptation Plan that are required under the 2002 Climate Change Response Act.

Several of the review's recommendations directly address the shortfalls of current planning legislation for addressing changing hazards. Of particular note is the linking of mitigation and adaptation in planning, requiring joint strategic plans and statutory Long Term Plans under the Local Government Act for each region, in conjunction with the territorial level of government. Under the current planning regime, the responsibility for these functions must be decided by agreement between regional and local councils, with the default being regional management. This has led to both levels of government usually trying to avoid responsibility for these functions, particularly regional councils which have little or no involvement in land-use planning. Also of note is the recommendation to introduce new planning tools that can be used for adaptive planning, such as dynamic adaptive policy pathways planning (Haasnoot et al., 2013) which is recommended in the national coastal hazards and climate change guidance for addressing uncertainties and changing risk (MfE, 2017; Lawrence et al., 2018). Stronger national direction is envisaged from the Government in response to the National Adaptation Plan under the Climate Change Response Act. Legacy effects (lock-in) are envisaged as being addressed in the Climate Change Adaptation Act through 
changes to "existing use rights" and provision of compensatory funding mechanisms.

In summary, the reforms now currently underway will put the focus on planning at a strategic level that can address key hazard and climate change risks, with stronger national direction and more joined up statutory processes and outcomes. To address the changing risks in an anticipatory manner, response pathways are envisaged as being embedded in plans as they are developed, rather than requiring multiple subsequent plan change processes. An inbuilt monitoring of change process through signals and triggers for shifting pathways ahead of the consequences of climate change is envisaged.

Statutory alignment and new statutes can clarify mandates, but they cannot assure successful implementation. The success of institutional reform for addressing changing hazard risk relies upon an enabling implementation environment, including organizational leadership, effective processes for genuine community engagement, practice capability and capacity, and monitoring of the changing risk through institutional arrangements and evolving science.

Our over-view of current practice demonstrates how statutory change, like the RMA in 1991, takes time to reset past practice. The changes, especially to the NZCPS in 2010, created an opportunity to reduce coastal hazard risk, but this was not taken up widely in practice because development pressures and absence of central government support for local authorities dealing with those pressures, dominated decision making. Indeed, over time the situation has enabled increasing exposure and vulnerability and a legacy impact that has become entrenched and is very hard to unbundle and with potentially large associated costs. Unlocking greater flexibility on the ground to remove risk through a managed staged retreat of settlements and their services over time, holds promise as a cost-effective alternative to the costs of temporary "protection" and "accommodation" measures in low-lying coastal areas, which continue to lock in expectations of ongoing protection and a sense of safety. This "levee effect" in Tobin (1995) entrenches risk and reduces the ability to adjust to changing conditions, transferring the risk to future generations in more costly forms that cannot keep up with the pace of climate change impacts. A further aspect which the reforms will need to address is the transfer of submerged areas back into the coastal marine area, where New Zealand law makes it subject to the Marine and Coastal Area (Takutai Moana) Act 2011, a complex statute which provides for both public and customary interests, and in some circumstances, ownership based on traditional rights. The issue of hard coastal protection, which has been generally discouraged in current policy, but which is commonly favored by communities under threat, is also likely to become subject to national direction through this statute.

New Zealand has the opportunity to mandate adaptive planning, tools and monitoring provisions as signaled by the RMA reform agenda, in a way not hitherto undertaken in statute or practice to date anywhere. The promise held out in terms of a single new coastal hazard planning statute which will override other planning instruments, and address land ownership and land uses in at-risk areas together, providing the means for compensation for current owners, is novel and potentially ground-breaking. The development of the policy and principles on which the new statute will rest, while at an early stage, is being watched with close interest by the many stakeholders within and outside of New Zealand also grappling with the effects of sea-level rise.

\section{DRIVING A TRANSITION TO ADAPTATION AS RISK MANAGEMENT}

Reflecting on the history, current practice and outcomes, and the planning system reforms currently underway, we now distill a set of principles that might drive us toward adaptation that can anticipate outcomes and develop flexible pathways to navigate the changing future.

To date our experience in New Zealand has followed a path where communities, planning practitioners and decision makers are learning by doing, seeing their peers and other communities experiment and fail, or succeed in achieving their objectives. Changes to the riskscapes and the responses to them (White and Lawrence, 2020) motivate new opportunities for advisors and communities to take up new approaches often enabled by science investment and which has practical value for decision makers (Kench et al., 2018; Kool et al., 2020; Lawrence et al., 2020b; Ryan et al., 2021) witnessed by the recognition of new approaches in the reform process in New Zealand (Randerson, 2020).

International colleagues and networks have collaborated on the development of new approaches and tools and highlighting them in the scholarly literature to be diffused through the IPCC assessments, thus giving them legitimacy (Lawrence and Haasnoot, 2017). They then have been embedded in national guidance (MfE, 2017) and proposed in law. However, this process is incremental and slow, not least because there are missing parts to enable implementation, but also in the understanding of the very nature of climate change as a policy problem that could inform more robust decision making by shifting practice toward adaptive planning processes. This understanding is in direct contrast to the established principle of "existing use rights" within current law, and landowner expectations of the provision for "reasonable use" of land also provided for within the RMA. Both concepts, make the implementation of adaptive planning complex in relation to land use, with no certainty of success.

\section{Understanding the Value of a Precautionary Approach}

The principles underlying adaptive planning are fundamentally driven by the precautionary principle, which in the climate change context guides its application. The precautionary principle arises from the notion of anticipating large and negative consequences or irreversibility and has evolved to mean that uncertainty should not be used as a defense for inaction in such circumstances, i.e., that avoidance or protective action should be taken ahead of full scientific proof of harm. The principle became codified in law and guiding frameworks as a "do no harm" principle [e.g., Principle 15 of the Rio Declaration 1992; Article 3.3 of the UN Framework Convention on Climate 
Change 1992]. These instruments use terms such as "anticipate, prevent or minimize," making the distinction between responses that occur after a climate "event" that causes damage and a precautionary one that suggests responses before a climate event. The precautionary principle is thus characterized as an anticipatory principle because it recognizes that climate change has the potential for widespread and large consequences for societal functioning which can be avoided, or at least minimized, and guiding implementation to avoid unnecessary costs that could be regretted. The precautionary principle has been embedded in the design of statutory instruments in New Zealand since at least 1994 (e.g., the first New Zealand Coastal Policy Statement under the RM Act), and in adaptive practice applied in other dynamic and changing systems, such as for consents in the marine area for aquaculture, and for the allocation of groundwater. ${ }^{5}$

Its utility relies upon how actual response measures within a quasi-legal context can accommodate uncertainty and dynamic change effects. When uncertainty and high consequences exist together, as they do for coastal hazards over the long term, using information as if it were certain is problematic (Fisher and Harding, 2006) potentially resulting in unintended consequences when the future turns out to be different. This is precisely why static instruments of planning are inappropriate for circumstances with changing risks. Focusing on uncertainty where there is a risk of "serious" and "irreversible damage" therefore can be a strength of the precautionary principle because the consequences could overwhelm the coping ability of the institutions in the future, thus compounding negative impacts on society.

\section{Understanding Deep Uncertainty to Match the Problem With the Planning Instrument Design}

Climate change presents to decision makers a type of problem that requires new approaches and tools that can anticipate risk, to avoid harm because of uncertainties about the future. These have been developed from the "deep uncertainty" tradition (Marchau et al., 2019) where "deep uncertainty" is defined as domains of decision making where the experts do not know or the parties to a decision cannot agree on the external context of the decision, how the system works and its boundaries, and/or the outcomes of interest from the system and/or their relative importance (Lempert et al., 2003). Deep uncertainty also arises from actions taken over time in response to unpredictable evolving situations (Haasnoot et al., 2013). These characteristics are all present in decision making on adaptation to climate change and in particular to ongoing sea-level rise.

Experience to date in New Zealand has been with adaptive planning outside of the regulatory processes. Dynamic Adaptive Policy Pathways (DAPP) planning has been used in coastal and

\footnotetext{
${ }^{5}$ Staged consents with conditions on duration, area, scale, intensity, and nature of the activity, with monitoring and reporting under the Exclusive Economic Zone and Continental Shelf (Environmental Effects) Act 2012; for aquaculture through regional coastal plans developed under the RMA; and for adaptive water allocations for groundwater consents.
}

flooding situations, for the assessment of coastal compartment risk, and for the development of preferred pathways that can be used to start the decision process for particular design parameters in structures and design flows for river management (Lawrence et al., 2019a,b). Signals and triggers along several pathways have been developed as management tools for giving warning and identifying the conditions under which current adaptations will no longer meet the objectives (Stephens et al., 2017, 2018). However, there is only one example in New Zealand where DAPP as a process has been enshrined in a statutory document (Table 2) based on the NZCPS as national direction. In that case, DAPP has been identified as the method which is to be used for future planning processes and decision-making in areas of identified coastal hazard risk, through a regional policy, but has not yet been given effect in the planning rules where land use activities and subdivisions are consented.

The planning law reforms that are under way have flagged the value of an anticipatory approach to adaptation. The review highlighted DAPP planning as an example that can be used to address changing climate risk and uncertainty, and indeed for any domain that has elements of dynamic change and uncertainty in the future around the pace and magnitude of change, such as in urban areas and ecosystems. The problem that DAPP can assist with under a planning regime where greater certainty is desired, yet certainty cannot be assured, is its ability to help identify adaptation options that do not lock in path dependency that increases climate change risk. By not prescribing a single predetermined solution, DAPP planning helps develop agreed suites of responses as options and pathways that can be implemented when pre-determined signals warn of an impending threshold, thus giving time to implement a more lasting option or pathway. Such signals and triggers for decision making can be defined through physical climate change, geomorphic change, social tolerance, cultural or economic values, as indicators of frequency (time) or damage (impact), for example.

\section{Participatory Governance}

Fundamental to democratic governance is the social contract with the governed. The governed comprise individuals, communities, different groups, sector interests, policy, and service delivery agents. Their interests are diverse, with each having different power and influence over decision makers. The closer governing agencies are to the people, the more difficult it is to deliver within an electoral cycle. The further away the governing agents are, the greater is the risk that decisions will be inappropriate or irrelevant. What gives decision making traction is credibility, salience, and legitimacy (Cash et al., 2003) of processes that are built on trust. Trust is built through working together in long term collaborative relationships, co-creating knowledge and confidence amongst the actors in "safe spaces," with an eye on the long term and an enabling environment that develops negotiating skills and breaks down power dominance in any one person or group (Vij et al., 2021). Where people's values and in particular their sense of place is threatened by ongoing sea-level rise and the response to it, participatory governance is critical for implementation of adaptive planning decisions (Schneider et al., 2020). This takes time but can be driven more 
effectively if mandates and roles are clear and decision-making processes are defined and mandated by statutory direction and oversight.

In New Zealand, such participatory roles are mandated under the Local Government Act where arguably the pressures from interests on elected officials have often led to perverse outcomes for coastal adaptation, through delay or adopting business as usual protection adaptations, or through the threat of or actual legal challenge to policy responses. ${ }^{6}$ These have had a chilling effect on proactive planning for known hazard risks (Lawrence et al., 2013). There is also evidence that high level national governance direction that is single purpose and short-term, may deliver perverse outcomes for adaptation (e.g., under the National Policy Statement for Urban Development 2020, which requires councils to identify growth areas to meet theoretical standard growth requirements). A more participatory governance model that relies upon a partnership approach using adaptive approaches could better bridge the respective mandates and roles and has been recommended in New Zealand and embedded in national guidance (MfE, 2017; CCATWG, 2018).

Assessments of the use of pathways approaches internationally have revealed the need for mechanisms that put values assumptions central in adaptive decision making and address social inequities (Gorddard et al., 2016). Understanding past change as a motivator for new and transformative futures (Fazey et al., 2016) has been emphasized, along with the important role of stakeholder participation in pathway development (Lin et al., 2017) as a way of addressing "power sensitive" design principles for climate change policies and their implementation (Vij et al., 2021).

\section{CONCLUSIONS}

The challenge going forward for reforming the planning process in New Zealand is how to turn a static planning process, with high expectations that land ownership conveys development rights, into a dynamic one that gives certainty of outcome sufficient to change society's "hard-wired" desire to be "protected," while at the same time governing from a participatory planning standpoint with a long view.

We proffer our perspective on the missing elements in the planning system that have been consistently identified as barriers to effective coastal adaptation (MfE Hawke's Bay Regional Council, 2020) and that if addressed could enable an anticipatory and adaptive planning system and practice to evolve more quickly.

1) Improved institutional frameworks and governance. Clarity of mandate and roles that reduce ambiguity and build capacity at the level of governance best suited to the decisionmaking domain and which are well coordinated across interdependent parts of a system, are arguably a foundation for reducing climate change risks as they change and worsen over

\footnotetext{
${ }^{6}$ Weir v Kapiti Coast District Council (2013) NZHC 3522, 19 December 2013; Awatarariki Residents Incorporated vs. Bay of Plenty Regional Council and Whakatane District Council (2020) NZEnvC 215.
}

time. Too many small local government agencies with the same responsibilities across two levels of local government has often created capacity and coordination difficulties for integration and resulted in perverse outcomes that are hard to shift in a world where the risks are changing quickly when decisions inertia is embedding legacy risks. Where regional and territorial local government functions exist in unitary councils, ${ }^{7}$ or where several councils co-join under a regional council, greater traction of proactive coastal planning has been observed, due to scale across a wider area and mean high water springs, consistent administration across regional and district responsibilities, resource efficiency and greater expertise.

2) Better community engagement about the coastal hazard risks that affect the direction of development, enables the values of current and future generations to be reflected in coastal risk assessments and opens up opportunities for innovative leadership and adaptation through well designed processes. Such processes can address and manage power interests which often have led to perverse outcomes increasing exposure to coastal hazards.

3) Equitable access to authoritative information, along with information on changing risk profiles.

4) Clearly stated statutorily binding objectives for vulnerable localities which set in place future pathways for change, and which avoid lock-in of increased risk, for example by anticipating change, that enabling building back better or somewhere else for sea-level rise, designing urban areas for more frequent flooding and through greater alignment across relevant statutes.

5) Using decision tools that are "fit for purpose" in a changing worsening situation, that can anticipate risk and uncertainty and enable flexible choices to be made by enabling a change in decision ahead of the risk being realized.

6) Effective monitoring systems that can track signals and triggers in a timely way, that are well embedded in risk management and decision-making processes of the responsible agencies, and that can be administered effectively as change occurs (in the physical environment and within organizations).

7) Legal changes to property rights, as they currently create perverse incentives for decision making on climate change risks and lead to ongoing increase in assets and number of people at risk.

8) Funding mechanisms targeted at anticipatory planning to avoid future risks and to address land use change where existing uses and assets are at risk.

While these suggestions are by no means the only missing parts to an effective statutory framework for climate change adaptation as risk management, they are the critical elements that can help embed an adaptive direction for planning practice and from which it will be difficult to resile. Like all reforms, the acid test is whether such changes can be implemented as

\footnotetext{
${ }^{7}$ Tasman Resource Management Plan, Marlborough Environment Plan, Clifton to Tangoio Coastal Hazards Strategy 2120.
} 
best practice or whether decisions continue to be made that lock in developments to ongoing risk by focusing on shortterm benefits of protection at the expense of future generations. Our paper has shown the nascent practice that could build the capability and capacity to anticipate climate risks and the reform mechanisms that could incorporate the concepts behind adaptation as risk management and thus leverage a transition to more adaptive coastal planning practice where sea-level rise is the dominant hazard.

\section{AUTHOR CONTRIBUTIONS}

JL conceived the paper and wrote the first draft. SA and LC contributed to the planning examples and with JL identified gaps in the planning system. All authors contributed to the article and approved the submitted version.

\section{FUNDING}

JL, SA, and LC were supported through the Resilience to Nature's Challenges National Science Challenge
Enabling Adaptation program funded by the New Zealand Ministry of Business, Innovation and Employment (GNS-RNC040) through the University of Auckland. JL and LC also received funding from the New Zealand SeaRise Endeavour Project through Victoria University of Wellington (RTUV1705). The funder was not involved in the study design, collection, analysis, interpretation of data, the writing of this article or the decision to submit it for publication.

\section{ACKNOWLEDGMENTS}

The authors wish to thank Gary Allis (Western Bay of Plenty District Council) for background papers on the Waihi Beach example, to Matt de Boer (Northland Regional Council) and Katy Simon (Kaipara District Council) for early discussions on the focus of the research, to Pere Hawes (Marlborough District Council) for updates on the Marlborough plan review, and to the Ministry for the Environment for helpful feedback on our research in the context of the RMA reforms. Helpful feedback was received from three reviewers which has strengthened that paper.

\section{REFERENCES}

Adger, W. N., Agrawala, S., Mirza, M. M. Q., Conde, C., O’brien, K. L., Pulhin, J., et al. (2007). "Assessment of adaptation practices, options, constraints and capacity," in Climate Change 2007: Impacts, Adaptation and Vulnerability. Contribution of Working Group II to the Fourth Assessment Report of the Intergovernmental Panel on Climate Change, eds M. Parry, O. Canziani, J. Palutikof, P. van der Linden, and C. Hanson (Cambridge, UK: Cambridge University Press), 717-743.

Boston, J., and Lawrence, J. (2018). Funding climate change adaptation: the case for a new policy framework. Policy Q. 14, 40-49. doi: 10.26686/pq.v14i2.5093

Cash, D. W., Clark, W. C., Alcock, F., Dickson, N. M., Eckley, N., Guston, D. H., et al. (2003). Knowledge systems for sustainable development. Proc. Natl. Acad. Sci. USA. 100, 8086-8091. doi: 10.1073/pnas.1231332100

CCATWG (2018). Adapting to Climate Change in New Zealand: Recommendations from the Climate Change Adaptation Technical Working Group. Wellington: CCATWG.

Challinor, A. J., Adger, W. N., Benton, T. G., Conway, D., Joshi, M., and Frame, D. (2018). Transmission of climate risks across sectors and borders. Philos. Trans. A Math. Phys. Eng. Sci. 376:20170301. doi: 10.1098/rsta.2017.0301

Fazey, I., Wise, R., Lyon, C., Campeanu, C., Moug, P., and Davies, T. (2016). Past and future adaptation pathways. Clim. Dev. 8, 26-44. doi: 10.1080/17565529.2014.989192

Fisher, E., and Harding, R. (2006). "The precautionary principle and administrative constitutionalism: the development of frameworks for applying the precautionary principle," in Implementing the Precautionary Principle, eds E. Fisher, J. Jones, and R. von Schomberg (Cheltenham; Northampton, MA: Edward Elgar Publishing), 113-136.

Gorddard, R., Colloff, M. J., Wise, R. M., Ware, D., and Dunlop, M. (2016). Values, rules and knowledge: adaptation as change in the decision context. Environ. Sci. Policy 57, 60-69. doi: 10.1016/j.envsci.2015.12.004

Haasnoot, M., Kwakkel, J., Walker, W., and ter Maat, J. (2013). Dynamic adaptive policy pathways: a method for crafting robust decisions for a deeply uncertain world. Glob. Environ. Change 23, 485-498. doi: 10.1016/j.gloenvcha.2012.12.006

Haasnoot, M., Lawrence, J., and Magnan, A. K. (2021). Pathways to coastal retreat. Science 372, 1287-1290. doi: 10.1126/science.abi6594

Hallegatte, S., Shah, A., Lempert, R., Brown, C., and Gill, S. (2012). Investment Decision Making Under Deep Uncertainty. Policy Research Working Paper. New York, NY: The World Bank.

IPCC (2014). “Summary for policymakers," in Climate Change 2014: Impacts, Adaptation, and Vulnerability. Part A: Global and Sectoral Aspects. Contribution of Working Group II to the Fifth Assessment Report of the Intergovernmental Panel on Climate Change, eds C. B. Field, V. R. Barros, D. J. Dokken, K. J. Mach, M. D. Mastrandrea, T. E. Bilir et al. (Cambridge and New York: Cambridge University Press), 1-32.

IPCC (2018). "Summary for policymakers," in Global warming of $1.5^{\circ} \mathrm{C}$. An IPCC Special Report on the Impacts of Global Warming of $1.5^{\circ} \mathrm{C}$ Above Pre-industrial Levels and Related Global Greenhouse Gas Emission Pathways, in the Context of Strengthening the Global Response to the Threat of Climate Change, Sustainable Development, and Efforts to Eradicate Poverty, eds V. Masson-Delmotte, P. Zhai, H. O. Pörtner, D. Roberts, J. Skea, P. R. Shukla, et al. (Cambridge, New York: Cambridge University Press).

Kench, P. S., Ryan, E. J., Owen, S., Bell, R., Lawrence, J., Glavovic, B., et al. (2018). Co-creating resilience solutions to coastal hazards through an interdisciplinary research project in New Zealand. J. Coastal Res. 85, 1496-1500. doi: 10.2112/SI85-300.1

Kool, R., Lawrence, J., Drews, M., and Bell, R. (2020). Preparing for sea-level rise through adaptive managed retreat of a New Zealand stormwater and wastewater network. Infrastructures 5:92. doi: 10.3390/infrastructures5110092

Lawrence, J., Bell, R., Blackett, P., Stephens, S., and Allan, S. (2018). National guidance for adapting to coastal hazards and sea-level rise: anticipating when and how to change pathway. Environ. Sci. Policy. 82, 100-107. doi: 10.1016/j.envsci.2018.01.012

Lawrence, J., Bell, R., and Stroombergen, A. (2019a). A hybrid process to address uncertainty and changing climate risk in coastal areas using dynamic adaptive pathways planning, multi-criteria decision analysis and real options analysis: a New Zealand application. Sustainability 11:406. doi: 10.3390/su11020406

Lawrence, J., Blackett, P., and Cradock-Henry, N. A. (2020a). Cascading climate change impacts and implications. Clim. Risk Manage. 29:100234 doi: 10.1016/j.crm.2020.100234

Lawrence, J., Boston, J., Bell, R., Olufson, S., Kool, R., Hardcastle, M., et al. (2020b). Implementing pre-emptive managed retreat: constraints and novel insights. Curr. Clim. Change Rep. 2020, 1-15. doi: 10.26686/wgtn.14502870.v1 
Lawrence, J., and Haasnoot, M. (2017). What it took to catalyse a transition towards adaptive pathways planning to address climate change uncertainty. Environ. Sci. Policy 68, 47-57. doi: 10.1016/j.envsci.2016.12.003

Lawrence, J., Haasnoot, M., McKim, L., Atapattu, D., Campbell, G., and Stroombergen, A. (2019b). "From theory to practice: a timeline of interventions by a change agent with the developers and users of Dynamic Adaptive Policy Pathways (DAPP)," in Decisionmaking Under Deep Uncertainty: From Theory to Practice, eds V. Marchau, W. Walker, and P. Bloeman (Berlin: Springer).

Lawrence, J., and Saunders, W. (2017). “The planning nexus between disaster risk reduction and climate change adaptation," Chapter 39 in Handbook of Disaster Risk Reduction Including Climate Change Adaptation, ed I. Kelman (Oxford: Taylor Francis Books).

Lawrence, J., Sullivan, F., Lash, A., Ide, G., Cameron, C., and McGlinchey, L. (2013). Adapting to changing climate risk by local government in New Zealand: Institutional practice barriers and enablers. J. Local Environ. 20, 298-320. doi: 10.1080/13549839.2013.839643

Lempert, R. J. (2019). “Robust decision making," in Decisionmaking Under Deep Uncertainty: From Theory to Practice, eds V. Marchau, W. Walker, and P. Bloeman (Berlin: Springer).

Lempert, R. J., Popper, S.W., and Bankes, S. C. (2003). Shaping the Next One Hundred Years: New Methods for Quantitative Long-Term Policy Analysis. Santa Monica, CA: RAND. Available online at: http://citeseerx.ist.psu.edu/viewdoc/ download? doi=10.1.1.446.7328\&rep=rep1\&type $=$ pdf $\quad$ (accessed 6 November 2021).

Lin, B. B., Capon, T., Langston, A., Taylor, B., Wise, R., Williams, R., et al. (2017). Adaptation pathways in coastal case studies: lessons learned and future directions. Coastal Manage. 45, 384-405. doi: 10.1080/08920753.2017.1349564

Manning, M., Lawrence, J., King, D. N., and Chapman, R. (2015). Dealing with changing risk: a New Zealand perspectve on climate change adaptation. Reg. Environ. Change 15, 581-594. doi: 10.1007/s10113-014-0673-1

Marchau, V., Walker, W., Bloeman, P., and Popper, S. (2019). Decision Making Under Deep Uncertainty: From Theory to Practice. Berlin: Springer.

MfE (2017). Coastal Hazards and Climate Change: Guidance for Local Government. Wellington: Ministry for the Environment Publication. Available online at: http://www.mfe.govt.nz/publications/climate-change/coastal-hazards-andclimate-change-guidance-local-government (accessed November 06, 2021).

MfE and Hawke's Bay Regional Council (2020). Challenges with Implementing the Clifton to Tangoio Coastal Hazards Strategy 2120 Case Study. Wellington: Ministry for the Environment. Available online at: https://environment. govt.nz/publications/challenges- with-implementing-the-clifton-to-tangoiocoastal-hazards-strategy-2120-case-study/ (accessed November 06, 2021).

Paulik, R., Lane, E., Williams, S., and Power, W. (2019). Changes in tsunami risk to residential buildings at Omaha Beach, New Zealand. Geosciences 9:13. doi: 10.3390/geosciences 9030113

Randerson, T. (2020). New Directions for Resource Management in New Zealand. Report of the Resource Management Review Panel.

Ruhl, J. (2010). Climate change adaptation and the structural transformation of environmental law. Environ. Law 40, 363-435. Available online at: https://www. jstor.org/stable/43267611

Ruhl, J. (2012). Panarchy and the law. Ecol. Soc. 17:31. doi: 10.5751/ES-05109-170331

Ryan, E. J., Owen, S. D., Lawrence, J., Glavovic, B., Robichaux, L., Dickson, M., et al. (2021). Formulating a 100-year strategy for managing coastal hazard risk in a changing climate: lessons learned from Hawke's Bay, New Zealand. Environ. Sci. Policy 127, 1-11. doi: 10.1016/j.envsci.2021.10.012

Schneider, P., Lawrence, J., Glavovic, B., Ryan, E., and Blackett, P. (2020). The rising tide of adaptation action: comparing two coastal regions of AotearoaNew Zealand. Clim. Risk Manage. 30:100244. doi: 10.1016/j.crm.2020. 100244

Smit, B., and Wandel, J. (2006). Adaptation, adaptive capacity and vulnerability. Glob. Environ. Change 16, 282-292. doi: 10.1016/j.gloenvcha.2006. 03.008

Stafford Smith, M., Horrocks, L., Harvey, A., and Hamilton, C. (2011). Rethinking adaptation for a $4^{\circ} \mathrm{C}$ world. Philos. Trans. R. Soc. A 369, 196-121. doi: $10.1098 /$ rsta.2010.0277

Stephens, S., Bell, R., and Lawrence, J. (2017). Applying principles of uncertainty within coastal hazard assessments to better support coastal adaptation. Mar. Sci. Eng. 5:20. doi: 10.3390/jmse5030040

Stephens, S., Bell, R., and Lawrence, J. (2018). Developing signals to trigger adaptation to sea-level rise. Environ. Res. Lett. 13:104004. doi: $10.1088 / 1748-9326 /$ aadf96

Tobin, G. A. (1995). The levee love affair: a stormy relationship. J. Am. Water Resour. Assoc. 31, 359-367.

Van Buuren, A., Lawrence, J., Potter, K., and Warner, J. (2018). "Introducing adaptive flood risk management in England, New Zealand, and the Netherlands: the impact of administrative traditions," in Special issue of Review of Policy Research, ed G. Peters, R. Biesbroek, and J. Tosun (Hoboken, NJ: Wiley).

Vij, S., Biesbroek, R., Stock, R., Gardezi, M., Ishtiaque, A., Groot, A., et al. (2021). "Power-sensitive design principles" for climate change adaptation policy-making in South Asia. Earth Syst. Govern. 9:100109. doi: 10.1016/j.esg.2021.100109

White, I., and Lawrence, J. (2020). Continuity and change in national riskscapes: a New Zealand perspective on the challenges for climate governance theory and practice. Cambridge J. Reg. Econ. Soc. 13, 215-231. doi: 10.1093/cjres/rsaa005

Conflict of Interest: SA was employed by Allan Planning and Research Ltd.

The remaining authors declare that the research was conducted in the absence of any commercial or financial relationships that could be construed as a potential conflict of interest.

Publisher's Note: All claims expressed in this article are solely those of the authors and do not necessarily represent those of their affiliated organizations, or those of the publisher, the editors and the reviewers. Any product that may be evaluated in this article, or claim that may be made by its manufacturer, is not guaranteed or endorsed by the publisher.

Copyright (c) 2021 Lawrence, Allan and Clarke. This is an open-access article distributed under the terms of the Creative Commons Attribution License (CC BY). The use, distribution or reproduction in other forums is permitted, provided the original author(s) and the copyright owner(s) are credited and that the original publication in this journal is cited, in accordance with accepted academic practice. No use, distribution or reproduction is permitted which does not comply with these terms. 